\section{ABERDEEN ROYAL INFIRMARY.}

CASES OF BURRELL'S OPERATION FOR RECURRENT DISLOCATION OF THE SHOULDER ; OPERATION FOR CERVICAI,

RIB ; TWO CASES OF RETAINED TESTIS TREATED

BY EUGENE HAHN'S ORCHIDOPEXY ; AND

A CASE OF INFLAMED RETAINED

TESTIS SIMULATING APPENDICITIS.

(Under the care of Mr. J. ScotT RIDDELL.)

THE five cases recorded below are all of considerable interest. In the first case Burrell's operation for recurrent dislocation was performed with a successful result. The best treatment for recurrent dislocation (especially in the shoulder, where it most usually occurs) is hardly yet determined. Fixation, with regular massage, may be tried for $t w o$ or three months, or even longer, but if after this luxation occurs the operation advocated by H. L. Burrell and R. W. Lovett ${ }^{1}$ deserves a trial. It consists essentially in shortening the capsule of the joint. In a normal shoulderjoint the capsule takes no part in retaining the head in place, for it is long and lax, but if it be greatly shortened t appears to prevent habitual dislocation. Excision of the joint has been performed ${ }^{2}$ and has given good results, but it is a more severe operation than that introduced by Burrell and Lovett. The case of cervical rib shows the discomfort which may arise from this developmental anomaly and the benefit produced by resection. The other three cases are good examples of retained testis. Two of these were treated by Hahn's method with very good results. The remaining cace is the most important, for an inflamed retained testis was mistaken for appendicitis and might earily have been treated by operation if the diagnostic acumen of the surgeon had not prevented such an unnecessary step. For the notes of the cases we are indebted to Dr H. Leith Murray, house surgeon.

CASE 1. Burrell's operation for recurrent dislocation of the shoulder. - A man, aged 42 years, was admited into the Aberdeen Royal Infirmary on Feb. 3rd, 1902. He gave a history of recurring dislocation of the right shoulder which had been specially troublesome for the past four month., having been 17 times out of place during that time, six weeks of which had been spent in a plaster-of-Paris casing without effect. The mere act of elevating the arm-as in putting on a coat-was sufficient to dislocate the arm. At his own request, after being under observation for a few day - he was operated on by Burrell's methods. A five-inch inction was made over the joint extending from above the coracoid process downwards and outwards. The deltoid exposed in the wound was incised as was also the upper twothirds of the insertion of the pectoralis major tendon. The sub,capularis was exposed, slightly incised, and the capsule exilnined during strong retraction. Great laxness (especially below and in front) was found, but there had been no rending. A sufficient ellipse of capsule was removed and the edges were united by a mattress silk suture which also included the subscapularis. The arm was kept well to the side and rotated outwards during the whole process as the head very readily slid into the subcoracoid fossa. The pectoralis major and deltoid were sutured with catgut and the skin with colloidin thread, an inclusive plaster-of-Paris jacket being applied over a sterilised gauze dressing. The stitches were removed on the tenth day through a fenestra and the wound was found to be healed. The plaster was removed at the end of three weeks and after a little gentle massage of the arm was re-applied. Daily massage was instituted a week later and by the end of six weeks from the operation the patient could easily raise the arm (with the scapula meantime fixed) to a right angle. When last heard of two months later he had almost complete movement and had had no recurrence.

CASE 2. A case of cervical rib.-A girl, aged 19 years, was admitted into the Aberdeen Royal Infirmary on April 29th, 1902. The patient gave a history of first beginning to suffer from pain over the right shoulder and in the right side of the neck about two years ago. She was growing rapidly at the time and the pain, at that time quite infrequent, gave her little trouble and was put down to "neuralgia." About six months before admission, however, it began to be much more severe and often kept her awake

1 American Journal of the Medical Sciences, August, 1897 2 Brit. Med. Jour., vol. ii., 1892, p. 1193 .
. mostly of a night. It was usually worse in the early morning and gave her little trouble during the day. The pain was said to be dull in character and, while it lasted, continuous seated low down in the neck on the right side and over and in front of the right shoulder-joint. It did not radiate elsewhere. On examination an abnormal bony prominence could be made out just above the middle of the clavicle on the right side. It felt about as large as an acorn, was firmly set, but was not painful to palpate. A skiagram showed a wellmarked cervical rib. Behind it articulated with the seventh cervical vertebra and in front became somewhat flattened out to articulate with a low-lying small cartilage. After consultation with her medical attendant (Dr. N. J. Sinclair of Brechin) it was decided to operate. A four-inch incision was made over the prominence in a vertical direction and deepened till the palpable part was reached. Seviral branches of the brachial plexus coursed across it and had to oe retracted. The prominence felt under the skin proved to be the enlarged end where it articulated with its cartilage. About three-quarters of an inch were resected by a Sigli's saw. The cartilage was fuund to lie close to the pleura. The wound was sutured in toto and healed by first intention. After the second day the patient had no pain and went home on the fourteenth day well pleased with the result of the operation. Two months later she reported herself as completely free from pain.

CASES 3 AND 4. Retained testis treated by Eugene Hahn's operation - Case 3 was that of a youth, aged 17 years, who was admitted into the Aberdeen Royai Infirmary on Jan. 11th, 1902, complaining of acute attacks of pain in the region of the right inguinal canal. On examination he was found to be suffering from a testis retained in that situation. A tender body about as large as a small walnut could be felt by pressing it downwards towards a finger in the external ring. He himself said that it occasionally descended temporarily into the scrotum, during which short periods he was free from pain. He described the pain as having for the past three years been very frequent and severe, rendering him for the time being unable to walk. He had not recognised the cause for the pain as being associated with the testis, but had put it down to a "stitch in the side," the pain always radiating well up the iliac region. Before three years ago he had a hernia on the right side which, however, did not trouble him much. He used to wear a truss, but had not done so for the time mentioned, as the rupture had ceased to come down. While under observation for the next nine days he had no pain, but the sweling in the canal did not alter in size. He was anæesthetised on Jan. 20th and the usual incision for inguinal hernia was made above Poupart's ligament. The sac of a congenital hernia was dissected free up to the ring. By a little ea-y manipulation from above the testis was lowered to the scrotum. A radical cure of the hernia by Halsted's method was then performed and the testis thereafter brought out through a half-inch opening in the fundus of the scrotum. This small scrotal wound was then stitched, leaving the testicle exposed outside like a mushroom. The hernial wound was completely sutured. Seven days later he was again anæsthetised, the scrotal sutures were removed: the testis was placed in the scrotum, and the wound was closed by a few celloidin thread sutures. Both wounds healed by first intention and the patient left the hospital on Feb. 11th. When last seen, three weeks later, the testicle lay well down in the scrotum and the youth had no discomfort of any kind.

Case 4 was that of a man, aged 21 years, who was admitted into the Aberdeen Royal Infirmary on Jan. 31 th complaining of pain in the right inguinal region. It had been present for four years; it occurred in attacks lasting a few days, but had not incapacitated him for work. On examination a small, non-tender body with a little testicular sensation could sometimes be made out lying nearly opposite the internal ring. There was no bubonocele. On Feb. 11th the patient was anæsthetised and a similar operation to that in the above case was performed. The testis was with some difficulty caught by a Liston's forceps and pulled into view. Some firm traction was necessary to allow of its being moored outside the scrotum. The second stage of the operation took place on Feb. 17th. Both wounds healed by first intention. 'The patient left the hospital on Feb. 28 th with the testis well fixed low down in the scrotum.

OASE 5. Inflamed retained testis simulating appendicitis.-A man, aged 47 years, was admitted into the 
Aberdeen Royal Infirmary about midday on April 28th, 1902. He was sent in from the country as "an urgent case of appendicitis with probable abscess." His illness began about a fortnight before admission and was the first time he had had any trouble in the region complained of. The first symptom was colicky pain at first centred around the umbilicus but by the next day localised to the right iliac region. It was increased by movement of the right leg. As his bowels had not been moved for several days (a frequent condition) his medical attendant prescribed repeated doses of sulphate of magnesia. Movement of the bowels, however, produced no relief. He began to feel sick but did not vomit. About the eighth day of the illness there was first felt a small tumour which had developed in the right iliac fossa. The patient himself had never noticed any swelling in that region before. During the next few days it rapidly increased in size and became much more tender. Poulticing did not relieve the pain. Finally, after a little delay from reluctance on the patient's part, he was removed to hospital. On examination the temperature was $97.4^{\circ} \mathrm{F}$., the pulse was 99 , and the respirations were 24 per minute. A rather firm and very tender sausage-shaped swelling, about four inches long by two inches broad, was felt deeply set in the right iliac fossa. It lay somewhat obliquely with its long axis directed downwards and inwards and it had its middle point rather below and external to McBurney's point. There was slight bulging of the skin over it but no discolouration or, indeed, any sign of an abscess. A rectal examination disclosed the same hard, tender mass. There was no fluctuation between the fingers. The rectum was packed witk hard freal masses. On making the routine examination the right half of the scrotum was found to be empty. Nothing was to be felt as far as the external ring. A large soap enema was given and at once produced a copious result. This was repeated with like success at seven o'clock and a small dose of saline aperient was subsequentjy given. After the first injection the pain began to abate and subsided steadily during the following days. The bowels were fi eely opened with castor oil. By 10 days the swelling was only about as large as a walnut, and it had entirely disappeared when, at his own request, he left the hospital wards three weeks after admission.

\section{期ledical Societies.}

\section{MEDICAL SOCIETY OF LONDON.}

\section{President's Opening Address.-Ovarian Tumour secondary to Cancer of the Breast.}

A MEeTing of this society was beld on Oct. 13th, Dr. W. H. Allchin, the President, being in the chair.

The treasurer's report and balance-sheet for the year ending Sept. 30th, 1902, as passed by the auditors, were presented and showed the society's finances to be in a satisfactory condition Votes of thanks to the retiring President (Dr. W. H. Allchin), the retiring secretary (Dr A. F. Voelcker), and the retiring members of the council were then proposed and carried by acclamation.

Mr A. Prarce Gould, the incoming President, then took the chair and delivered his opening address. He commenced by conveying the thanks of the society to Dr. W. H. Allchin for the presidential badge which he had presented to the society. In opening the 130th session of the Medical Society of London Mr. Gould made reference to the loss which they had suffered by the death of Professor Rudolf Virchow who had exercised so marked an influence upon two generations of pathological observers. Reference was made t) Professor Virchow's breadth of mind and the wide extent of his knowledge and interests. It was doubtful, the President remarked, if the medical profession always took its rightful part in the political life of a nation. The advance in medical science during the last century was then referred tw and the great lack of knowledge which still existed. But a review of the past formed a bas is for hope that further alvance would be made in the future. The President concluded by emphasising the value of medical societies in yeneral for the diffusion of know]edge, for criticism encouragement, and the interchange of ideas.

Mr. J. BLAND-SUTwon read a paper on a case of Large Ovarian Tumour secondary to Cancer of the Breast. The patient was a woman, aged 35 years, the mother of one child, from whom the right breast was removed for cancer in January, 1894. This was followed by recurrence three years, and again four years, afterwards, removal being resorted to on each occasion. In January, 1899, the left breast became involved and it was in turn removed. The patient remained quite well for two years, but in January, 1902, a tumuur appeared in the abdomen which was removed in March of this year. The patient had made satisfactory progress up to the present time. Five gallons of fluid were removed in addition to the large, solid ovarian tumour exhibited. The tumour measured seven inches in its two chief diameters, was dense, hard, and presented the microscolic

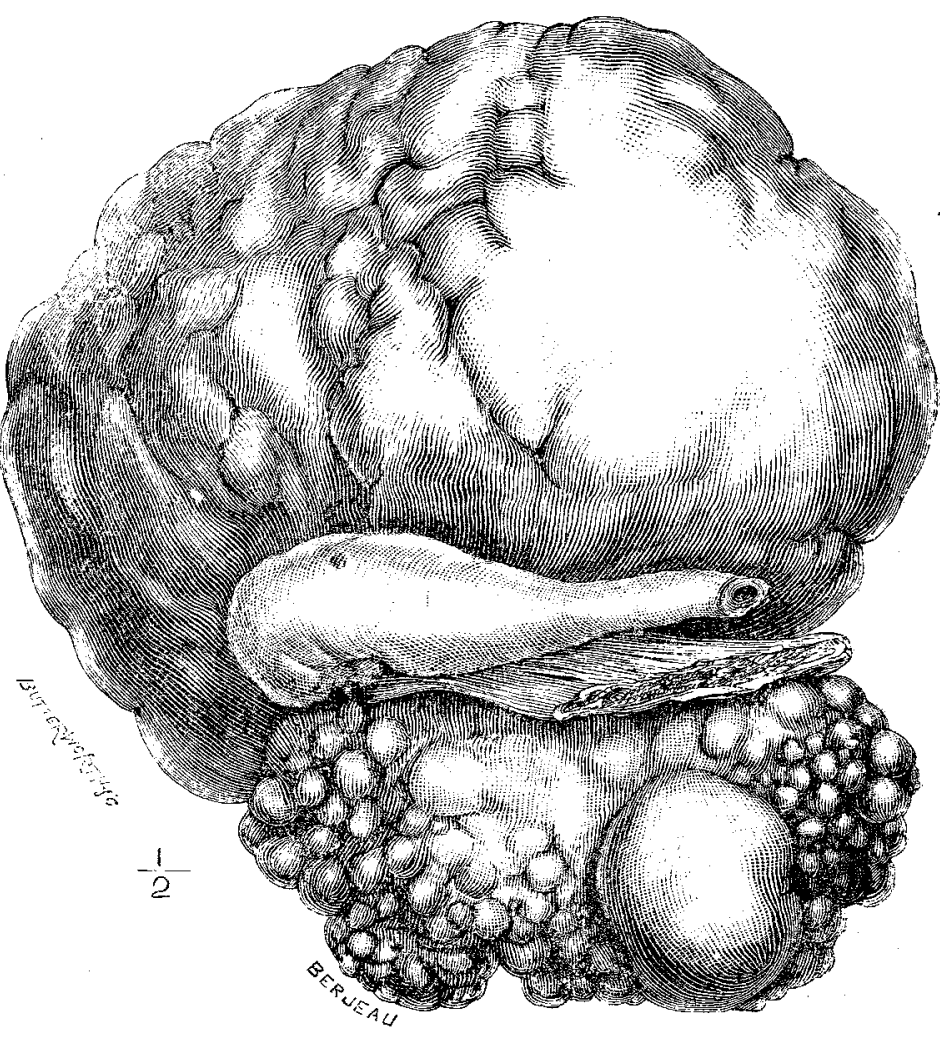

structure of mammary cancer in its most typical form. The case presented the most remarkable example of a cancerous growth in an ovary secondary to cancer in the breast which had come under his (Mr. Bland-Sutton's) notice It also raised the question of the relative frequency with which cancer attacked both breasts concurrently or after an interval of months or years. Buth conditions were very unusual in Mr. Bland-Sutton's experience. He had come to the conclusion that when a woman had one breast removed for cancer she was five times more likely to have secondary deposits of cancer in one or both ovaries than in the remaining breast.-Mr. JONATH AN HuTCHINSON, jun., remarked on the size of the tumour exhibited and its limitation to one ovary. He had twice met with recurrence of cancer in the ovaries secondary to the breast, b:t both were smaller than the specimen shown. Details were given of one of two cases which was remarkable for the rapid and widespreac deposit of nodules in the skin. The recurrence of cancer in the opposite breast was undoubtedly rare. It was formerly regarded as a contra-indication to operation, but he (Mr. Hutchinson) had known such operations performed upon the second breast to be followed by the most successful results. Dr. J. VINCENT BELL (Rochester) referred to a case in which recurrence took place in the opposite breast in a woman about 35 years of age No further deposits had occurred since the uperation which was performed five years ago. The PRESIDENT remarked that the specimen was unique in its size. As to the frequency of recurrence in the opposite breast he could not agree that it was altigether rare. The most interesting question was whether the tumorr which occarred in the opposite breast was a de novo formation or a true secondary deposit, and he inclined to the former view, cases being referred to by way of illustration in which the structure of the tumour of the second breast differed in some way from that of the tumour in the breast first involved. $\mathrm{He}^{\mathrm{e}}$ would certainly advise operation on the second breast without delay. He asked Mr. Bland-Sutton on what data 